\title{
Mechanistic Investigation of Oxidation of Aromatic Primary Alcohol by Polymer Supported Oxidizing Agent
}

\author{
VILAS Y. SONAWANE \\ Department of Chemistry, B.Raghunath Arts, Commerce and Science College, \\ Parbhani-434 401, Maharashtra, India \\ sonawane_vy@rediffmail.com
}

Received 23 May 2016 / Accepted 5 June 2016

\begin{abstract}
The kinetic of chromium(VI) catalyzed oxidation of 1-phenylalcohol has been studied by the rate of disappearance of $[\mathrm{Cr}(\mathrm{VI})]$. The reaction is zero order with respect to $[\mathrm{Cr}(\mathrm{VI})]$. The reagent supported on anion exchange resin was found to be more efficient in the oxidation reaction. The reagent is very easily separated from the reaction mixture and can be manually removed from the reaction mixture, which remains clear during and after the reaction. The kinetic of oxidation of 1-phenylethanol with chromic acid supported on anion exchange resin like Amberlite IRC-178 [ $\left.\mathrm{Cl}^{-}\right]$ in 1, 4-dioxane has been studied. The reaction is found to be of zero order each in concentration of alcohol and oxidant. The reaction constants involved in the mechanism and the activation parameters have been calculated. There is a good agreement between observed and calculated rate constants under different experimental conditions. Acetophenone was detected as end product.
\end{abstract}

Keywords: Kinetics, Reaction mechanism, Oxidations, Chromium(VI), Polymer-supported chromic acid, Thermodynamic parameters

\section{Introduction}

Transition metals in the higher oxidation state generally can be stabilized by chelating with suitable complex agent ${ }^{1-4}$. The kinetics and mechanism of oxidation of chromium(VI) has been well studied, chromic acid being one of the most versatile available oxidizing agents, reacting with diverse substrates. Now a day the development of newer chromium(VI) reagents ${ }^{5-11}$ for the oxidation of organic substrates continues to be of interest. Chromium is one of the most widely distributed heavy metals in the earth's crust. It is normally found into oxidation states i.e. $\mathrm{Cr}(\mathrm{III})$ and $\mathrm{Cr}(\mathrm{V})$. Chromium is required in small quantities as an essential trace metal. Most of the biological tissues contain $\mathrm{Cr}(\mathrm{III})$ which is usually non toxic, where as $\mathrm{Cr}(\mathrm{VI})$ is a highly toxic for the metal to the organism ${ }^{12}$. The selective oxidation of primary alcohols and secondary alcohols into their corresponding aldehydes (or carboxylic acids) and ketones is one of the important transformations in modern organic synthesis. 
In the present investigation, we now report the oxidation of 1-phenylethanol by polymersupported chromic acid. Amberlite IRC-178 $\left[\mathrm{Cl}^{-}\right]$is the strong anion exchange resin are supported on chromium(VI) oxide and used as an oxidant.

\section{Experimental}

All the reagents used were of highest purity available. Aqueous solution of chromic acid was prepared always afresh and standardized iodometrically.

Amberlite IRC-178 [Cl]

It is weak anion exchange resin offered by Aldrich having gel type with mesh16-50 bead size having moisture 65 percentages with $\mathrm{pH}$ range 1.5-14.

\section{Preparation of supported oxidizing agent}

The supported oxidizing agent was prepared by reported method ${ }^{13-15}$. The chloride form of Amberlite IRC-178 $\left[\mathrm{Cl}^{-}\right]$(a macro reticular anion exchange resin) containing a quaternary ammonium group $\left(10 \times 10^{-3} \mathrm{~kg}\right)$ was stirred with a saturated solution of chromium trioxide $\left(5 \times 10^{-3} \mathrm{dm}^{3}\right)$ in water $\left(30 \times 10^{-3} \mathrm{dm}^{3}\right)$ for $30 \mathrm{~min}$ at room temperature using a magnetic stirrer. The chloride ion was readily displaced and $\mathrm{HCrO}_{4}{ }^{-}$form of resin was obtained in $30 \mathrm{~min}$. The resin was successively rinsed with water, acetone and THF and finally dried in vaccum at $323 \mathrm{~K}$ for $5 \mathrm{~h}$. The dried form of the resin was stored and used throughout the kinetic study.

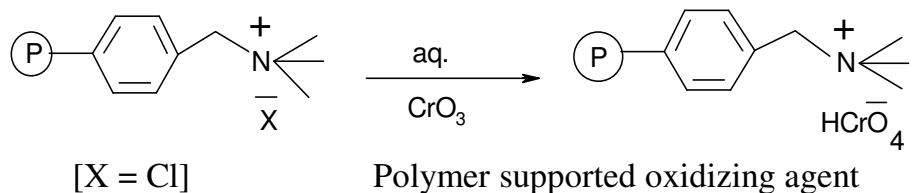

\section{Determination of the capacity of chromate form of the polymeric reagent}

The capacity of the chromate form of Amberlite IRC-178 $\left[\mathrm{Cl}^{-}\right]$polymeric reagent was determined by iodometrically. The capacity of the chromate form of resin was $1.1 \mathrm{meq} / \mathrm{g}$ and used for kinetic study throughout work.

\section{Method of kinetics}

The reaction mixture for the kinetic run was prepared by mixing alcohol, oxidant and solvent. The reaction was carried out either constant stirring using magnetic stirrer and at a constant temperature $318 \pm 1 \mathrm{~K}$. At different time interval, the reaction mixture was withdrawn using a micropipette. The aliquot thus withdrawn was taken in a stoppered test tube containing $5 \times 10^{-3} \mathrm{dm}^{3}$ of 1, 4-dioxane and subjected to spectral analysis. The absorbance of the product formed was measured using SL 159 UV-Visible spectrophotometer. Duplicate kinetic runs showed that the rate constants were reproducible to within $\pm 1 \%$.

\section{Induced polymerization test}

The possibility of formation of free-radicals was examined by adding acrylonitrile to the partially oxidized reaction mixture. The formation of a white precipitate indicates that the reaction proceeds by free-radical mechanism.

\section{Product analysis}

The oxidation of 1-phenylethanol leads to the formation of acetophenone. The product formed was analyzed by their 2, 4-dinitrophenylhydrazine derivatives. The precipitated 
2, 4-dinitrophenylhydrazone (DNP) was filtered off, the product was then vacuum dried, weighed and recrystallised from alcohol. The yield of DNP recrystallisation with the DNP of acetophenone was $96 \%$. The product also identified either by comparison with authentic samples or by UV, FT-IR spectral and elemental analysis. The IR spectra were recorded on a Jasco FT-IR spectrophotometer using $\mathrm{KBr}$ pellets. The melting point of 2, 4-dinitro-phenylhydrazone derivative of 1-phenylethanol is $237{ }^{\circ} \mathrm{C}(510 \mathrm{~K})$.

\section{IR data}

A sharp band at $1683 \mathrm{~cm}^{-1}$ for $-\mathrm{C}=\mathrm{O}$ stretching mode, $1585 \mathrm{~cm}^{-1}$ aromatic $(-\mathrm{C}=\mathrm{C}-)$, $3063 \mathrm{~cm}^{-1}$ (-C- H stretch).

\section{Results and Discussion}

\section{Effect of varying weights of oxidant}

The order with respect to weights oxidant is zero, as the plots of absorbance against time were linear in all runs and observed rate constant are fairly constant between 100 to $160 \times 10^{-6} \mathrm{~kg}$ of oxidant at constant concentration of solvent $\left(1,4-\right.$ dioxane, $\left.5 \times 10^{-3} \mathrm{dm}^{3}\right)$ and 1-phenylethanol $\left(12.3 \times 10^{-3} \mathrm{~mol} / \mathrm{dm}^{-3}\right)$, the effect of varying weights of oxidant on zero order rate constant as shown in Table 1.

Table 1. Effect of varying weights of oxidant on reaction rate at $318 \mathrm{~K}$

\begin{tabular}{lccccc}
\hline Rate constant & $\rightarrow$ & \multicolumn{4}{c}{$\mathrm{k} \mathrm{x} \mathrm{10^{-4 }} \mathrm{mol} \mathrm{dm}^{-3} \mathrm{~s}^{-1}$} \\
\hline Oxidant $\times 10^{-6} \mathrm{~kg} \rightarrow$ & 100 & 120 & 140 & 160 \\
Amberlite IRC-178 $\left[\mathrm{Cl}^{-}\right]$ & 1.35 & 1.36 & 1.38 & 1.39 \\
\hline
\end{tabular}

Effect of varying concentrations of 1-phenylethanol

At a varying concentration of 1-phenylethanol $\left(8.20\right.$ to $\left.20.4 \times 10^{-3} \mathrm{~mol} / \mathrm{dm}^{3}\right)$, constant weights of oxidant $\left(70 \times 10^{-6} \mathrm{~kg}\right)$ and constant concentration of solvent $\left(1,4\right.$-dioxane, $\left.5 \times 10^{-3} \mathrm{dm}^{3}\right)$, zero order rate constant (Table 2) was found.

Table 2. Effect of varying concentrations of 1-phenylethanol

\begin{tabular}{|c|c|c|c|c|}
\hline Rate constant $\rightarrow$ & & $\mathrm{k} \times 10^{-}$ & $\mathrm{mol} \mathrm{dm}{ }^{-3} \mathrm{~s}^{-1}$ & \\
\hline 1-Phenylethanol $\rightarrow$ & $\begin{array}{l}8.20 \times 10^{-3} \\
\mathrm{~mol} / \mathrm{dm}^{3}\end{array}$ & $\begin{array}{l}12.3 \times 10^{-3} \\
\mathrm{~mol} / \mathrm{dm}^{3}\end{array}$ & $\begin{array}{l}16.4 \times 10^{-3} \\
\mathrm{~mol} / \mathrm{dm}^{3}\end{array}$ & $\begin{array}{l}20.4 \times 10^{-3} \\
\mathrm{~mol} / \mathrm{dm}^{3}\end{array}$ \\
\hline Amberlite IRC-178 $\left[\mathrm{Cl}^{-}\right]$ & 1.46 & 1.49 & 1.50 & 1.51 \\
\hline
\end{tabular}

\section{Effect of varying dielectric permittivity of the medium on the reaction rate}

It was found that as the dielectric constant of the medium increased, this including $\mathrm{r}^{*}<\mathrm{r}$ (Where $\mathrm{r}^{*}$ and $\mathrm{r}$ refer to the radii of the reactant species and activated complex respectively) at constant concentration of 1-phenylethanol $\left(12.3 \times 10^{-3} \mathrm{~mol} / \mathrm{dm}^{3}\right)$ and constant concentration of oxidant $\left(70 \times 10^{-6} \mathrm{~kg}\right)$, solvent $\left(5 \times 10^{-3} \mathrm{dm}^{3}\right)$ as shown in Table 3 .

Table 3. Effect of varying dielectric permittivity

\begin{tabular}{llllll}
\hline Rate constant $\rightarrow$ & \multicolumn{4}{c}{$\mathrm{k} \mathrm{x} \mathrm{10} 0^{-4} \mathrm{~mol} \mathrm{dm}^{-3} \mathrm{~s}^{-1}$} \\
\hline Solvent $\left[5 \times 10^{-3} \mathrm{dm}^{3}\right] \rightarrow$ & $\mathrm{C}_{6} \mathrm{H}_{12}$ & $\mathrm{CCl}_{4}$ & $1,4-$ dioxane & $\mathrm{CHCl}_{3}$ \\
Dielectric constant $\rightarrow$ & 2.00 & 2.17 & 2.28 & 4.81 \\
Amberlite IRC-178 $\left[\mathrm{Cl}^{-}\right]$ & 1.15 & 1.39 & 1.66 & 2.40 \\
\hline
\end{tabular}




\section{Effect of varying temperature}

The reaction was carried out at four different temperatures under otherwise similar reaction conditions to study the effect of temperatures on the rate of reaction. It was observed that, the rate of reaction increased with an increase in the temperature (Table 4). The activation parameters like energy of activation $(\mathrm{Ea})$, enthalpy of activation $\left(\Delta \mathrm{H}^{\#}\right)$, entropy of activation $\left(\Delta S^{\#}\right)$ free energy of activation $\left(\Delta G^{\#}\right)$ the high positive values of free energy of activation indicates that the transition state is highly solved and frequency factor (A) were calculated by determining values of $\mathrm{k}$ at different temperatures (Table 5).

Table 4. Effect of varying temperature

\begin{tabular}{|c|c|c|c|c|}
\hline Rate constant $\rightarrow$ & & $\times 10^{-4}$ & $\mathrm{dm}^{-3} \mathrm{~s}$ & \\
\hline Temperature $\mathrm{K} \rightarrow$ & 313 & 318 & 323 & 328 \\
\hline Amberlite IRC-178 $\left[\mathrm{Cl}^{-}\right]$ & 1.76 & 1.88 & 1.99 & 2.25 \\
\hline
\end{tabular}

Table 5. Activation parameters

\begin{tabular}{lc}
\hline Energy of activation $(\mathrm{Ea}) \mathrm{kJ} \mathrm{mol}^{-1}$ & $79 \pm 4$ \\
Enthalpy of activation $\left(\Delta \mathrm{H}^{\#}\right) \mathrm{kJ} \mathrm{mol}^{-1}$ & $59 \pm 3$ \\
Entropy of activation $\left(\Delta \mathrm{S}^{\#}\right) \mathrm{JK} \mathrm{mol}^{-1}$ & $-69 \pm 2$ \\
Free energy of activation $\left(\Delta \mathrm{G}^{\#}\right) \mathrm{kJ} \mathrm{mol}^{-1}$ & $353 \pm 2$ \\
Frequency factor $(\mathrm{A}) \times 10^{-5} \mathrm{~s}^{-1}$ & $4 \pm 0.5$ \\
\hline
\end{tabular}

The proposed path for the reaction of chromium(IV) then makes possible a different. Thus based on experimental results, obtained for the oxidation of 1-phenylethanol by polymer support, the reaction was found to be zero order. Initially $\operatorname{Cr}(\mathrm{VI})$ is reduced to $\mathrm{Cr}(\mathrm{IV})$. It is likely to react with another $\mathrm{Cr}(\mathrm{VI})$ to generate $\mathrm{Cr}(\mathrm{V})$ which is then reduced in a fast step to the ultimate product $\mathrm{Cr}(\mathrm{III})$. Such a sequence of reactions in $\mathrm{Cr}(\mathrm{VI})$ oxidation is well known ${ }^{17-19}$.

On the basis of above discussion and experimental results the following reaction schemes is proposed for $\mathrm{Cr}(\mathrm{VI})$ catalyzed oxidation of 1-phenylethanol.The mechanism is suggested in Scheme 1-5 and involves ester formation.

1) The polymer supported reagent reacts with a molecule of alcohol to form a chromate ester.
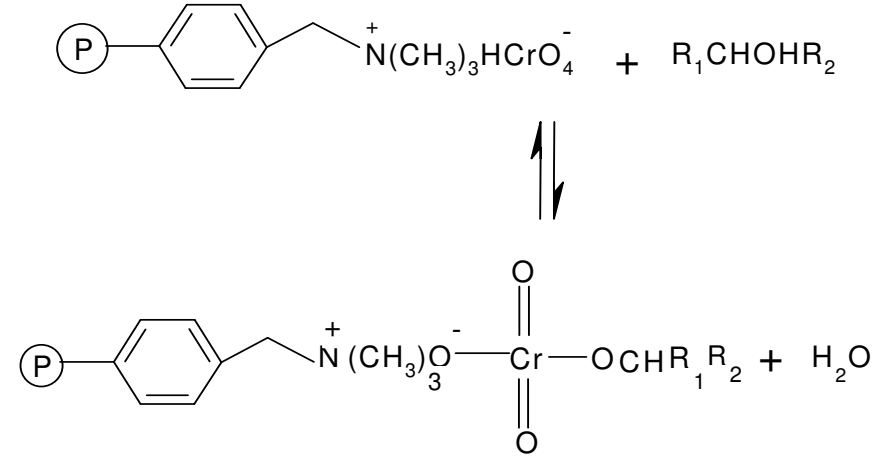

\section{Scheme 1}

2) The ester formed will decompose into ketone and the intermediate chromium(IV) will be formed in the second and slow step. 


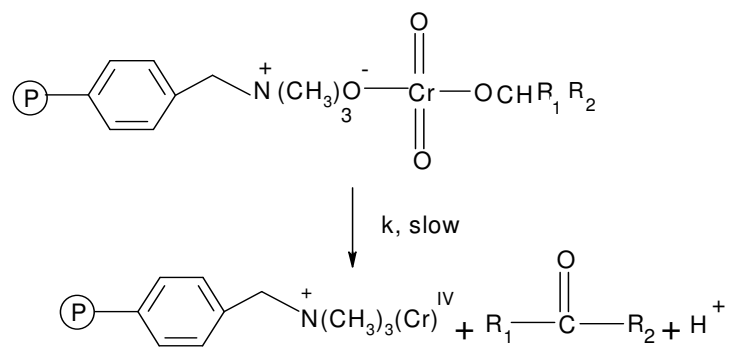

Scheme 2

3) The intermediate chromium(IV) thus reacts with another alcohol molecule to produce a free radical species. The free radical species formation in the reaction was confirmed by the polymerization of added acrylonitrile or addition of acidified methanol into the reaction mixture.

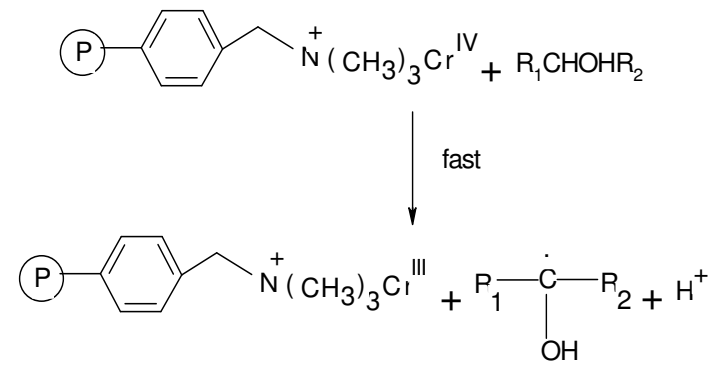

Scheme 3

4) Subsequently the free radical will react with another oxidant site in the polymeric reagent in a fast step leading to the formation of chromium(V).

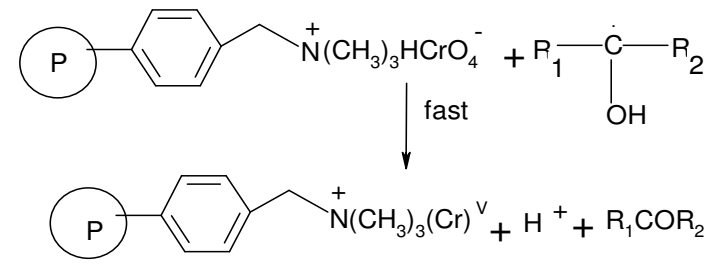

\section{Scheme 4}

5) The intermediate chromium(V) in the last step reacts with 1-phenylethanol produce acetophenone. The test for formation of chromium(V) and (IV) by the characteristic induced oxidation of iodide ${ }^{20}$ and manganese(II) ${ }^{21}$ were not probably due to heterogeneity of the reaction mixture.

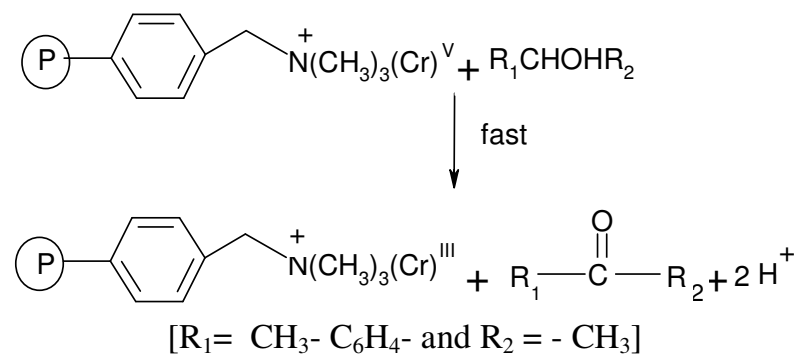

\section{Scheme 5}




\section{Conclusion}

The linearity of absorbance against time plots and constancy of the zero order rate constants indicate that the reaction neither depends on the polymeric reagents nor on the alcohol concentration. This anomalous nature of the reaction may be because of the fact that the oxidant is taken in the form of solid supported on polymer. Polymer supported oxidizing agent proved to be exclusively selective towards the oxidation of 1-phenylethanol, giving acetophenone as the only product.

We obtained zero order dependence with rate constant $k$ of the second slow step in which product acetophenone was obtained. Based on the experimental observations a probable mechanism is suggested.

\section{Acknowledgement}

The author is thankful to the University Grants Commission, New Delhi, India for the financial support of this major research project sanctioned F.No.42-253/2013(SR). The author is grateful to the C-MET, Pune, Maharashtra, India for providing some instrumental facilities.

\section{References}

1. Song W Y, Li W K and C P Jia, Chem J Chin Univ., 1999, 20(11), 1767-1771.

2. $\quad$ Song W Y and Liu H M, Chin J Inorg Chem., 2000, 16(4), 607.

3. Shan J H, Qian J and Zhai T Y, Chin J Inorg Chem., 2003, 19, 843.

4. Lakshmi S and Renganathan R, Int J Chem Kinet., 1996, 28(10), 713-720; DOI:10.1002/(SICI)1097-4601(1996)28:10<713::AID-KIN1>3.0.CO;2-Q

5. Corey E J and Schmidt G, Tetrahedron Lett., 1979, 20(5), 399-402; DOI:10.1016/S0040-4039(01)93515-4

6. Bhattacharjee M N, Choudhari M K, Dasgupta H S, Roy N and Khating D T, Synthesis, 1982, 58.

7. E. J. Corey, E.P.M.Barette and Margrious P A, Tetrahedron Lett., 1985, 24(51), 5855-5858; DOI;10.1016/S0040-4039(01)81703-2

8. Climinale F, Camporeale M, Mello R, Troisi L and Curci R, J Chem Soc Perkon Trans., 1989, 2, 417-423; DOI:10.1039/P29890000417

9. Sharma G G and Mahanti M K, Bull Soc Chem Fr., 1991, 128, 449.

10. Balasubramanian K and Pratibha V, Indian J Chem Sec B., 1986, 25, 326.

11. Narayana B and Tam Cherian, J Braz Chem Soc., 2005, 16(2), 197-201; DOI:10.1590/S0103-50532005000200011

12. Buglas A J and Waterhouse J S, J Chem Edu., 1987, 64, 3712.

13. Cainelli G, Cardillio G, Orena M and Sardri S, J Am Chem Soc., 1976, 98, 6767.

14. Brunlet T, Jouitteau C and Gelhard G, J Org Chem., 1986, 51, 4016-4022; DOI:10.1021/jo00371a019

15. Mosher W A, Clement H and Hillard R L, J Am Chem Soc., 1993, 29(4), 565.

16. Watanabe W and Westheimer F H, J Chem Phys., 1979, 61, 17.

17. Salunke M M, Salunke D G, Kanade A S, Mane R B and Wadgaonkar P P, Synth Commun., 1990, 2B, 1143.

18. Matsuo J, Kawana A, Pudhon K and Mukaiyama T, Chem Lett., 2002, 250.

19. Hutchins R O, Natale N R and Cook W J, Tetrahedron Lett., 1977, 18(48), 41674169; DOI: 10.1016/S0040-4039(01)83456-0

20. Buglas A J and Waterhouse J S, J Chem Edu., 1987, 64, 3712.

21. Espenson J H, J Am Chem Soc., 1964, 86(23), 5101-5107; DOI:10.1021/ja01077a012 